\title{
A novel hirudin derivative characterized with anti-platelet aggregations and thrombin inhibition
}

\author{
Wei Mo · Yan-Ling Zhang · Hong-Shan Chen • \\ Long-Sheng Wang $\cdot$ Hou-Yan Song
}

Published online: 9 November 2008

(C) The Author(s) 2008. This article is published with open access at Springerlink.com

\begin{abstract}
Background Hirudin is an anti-coagulative product of the salivary glands of the medicinal leech Hirudo medicinalis. It is a powerful and specific thrombin inhibitor. Peptides containing the RGD motif competitively inhibit the binding of fibrinogen to GP IIb/IIIa on the platelets, thus inhibiting platelet aggregation. Results We have constructed a recombinant RGD-hirudin (r-RGDhirudin) by fusing the tripeptide RGD sequence to the native hirudin (wt-hirudin). The r-RGD-hirudin was expressed at high levels in Pichia pastoris, and was purified to $\sim 97 \%$ homogeneity. The specific anti-thrombin activity of purified r-RGD-hirudin is $12,000 \mathrm{ATU} / \mathrm{mg}$, which is equivalent to wt-hirudin, but only r-RGD-hirudin can inhibit platelet aggregation. The biological effects of
\end{abstract}

Wei Mo and Hou-Yan Song planned and designed the experiment. Yan-Ling Zhang, Hong-Shan Chen, Long-Sheng Wang carried out the experimental work.

Wei Mo and Hou-Yan Song processed, interpreted the results and drew conclusions. Wei Mo wrote the manuscript. All authors have read and approved the manuscript.

W. Mo · Y.-L. Zhang · H.-S. Chen · L.-S. Wang ·

H.-Y. Song $(\square)$

The Key Laboratory of Molecular Medicine,

Ministry of Education, Fudan University, P.O. Box 238,

138 Yixueyuan Road, Shanghai 200032, China

e-mail: hysong@shmu.edu.cn

W. Mo

e-mail:weimo1025@shmu.edu.cn

Y.-L. Zhang

e-mail: zhangyl@ shmu.edu.cn

H.-S. Chen

e-mail: chenhongshan999@ sohu.com

L.-S. Wang

e-mail: wanglsh@shmu.edu.cn
r-RGD-hirudin on Thrombin Time (TT), Prothrombin Time (PT), Activated Partial Thromboplastin Time (APTT), Bleeding Time (BT), maximum platelet aggregation (PAGm) induced by ADP were studied in rabbit model and compared with that of wt-hirudin. The rabbits were infused r-RGD-hirudin had prolonged TT, PT, and aPTT which were similar to that of wt-hirudin; but only r-RGD-hirudin was capable of inhibiting PAGm. Histopathological analyses showed that r-RGD-hirudin was two to three times more effective than wt-hirudin in preventing thrombosis. Conclusions r-RGD-hirudin can potentially be used as a novel anti-coagulant for the prevention of thrombosis after carotid artery anastomosis or in other thrombotic events.

Keywords Recombinant r-RGD-hirudin .

Novel anti-coagulant . Carotid artery anastomosis .

Anti-thrombotic therapy

\section{Abbreviations \\ Glycoprotein IIb/IIIa GP IIb/IIIa}

\section{Introduction}

Hirudin is an anti-coagulative product of the salivary glands of the medicinal leech Hirudo medicinalis. It is a powerful and specific thrombin inhibitor. Unlike heparin, which acts by binding to anti-thrombin III, hirudin binds directly to thrombin, and inhibits fibrin-bound as well as fluid-phase thrombin. It also inhibits fibrinogen clotting and thrombin-catalysed haemostatic reactions [1].

The native hirudin (wt-hirudin) is a single-chain, carbohydrate-free polypeptide containing 65-66 amino acids 
with a molecular weight of 7,000 Da. Wt-hirudin has a trisulfide-linked core structure, forming a compact $\mathrm{NH}_{2}$ terminal domain and a long $\mathrm{COOH}$-terminal extended domain. The crystal structure of hirudin-thrombin complex revealed abundant polar and apolar interactions between these two molecules, which may account for the tight affinity and specificity of hirudin binding [2].

Adhesion of platelets to vessel walls, their activation, and aggregation are key events in blood coagulation. On activated platelets, the glycoprotein IIb/IIIa (GP IIb/IIIa) functions as a receptor for fibrinogen to mediate platelet aggregation and cross-linking. The capability of GP IIb/IIIa to bind to fibrinogen and other adhesive proteins is due to its ability to recognize the Arg-Gly-Asp (RGD) motif within their sequences. Peptides containing the RGD motif or RGD itself competitively inhibit the binding of fibrinogen to GP IIb/IIIa on the platelets, thus inhibiting platelet aggregation [3]. Adelman et al. [4] showed that peptides with RGD efficiently prevent platelet aggregation induced by ADP.

In the present study, we engineered a novel bi-functional hirudin molecule, r-RGD-hirudin, by fusing an RGD tripeptide to the wt-hirudin. We reasoned that this r-RGDhirudin should be able to inhibit both thrombin and platelet aggregation. We then studied r-RGD-hirudin as a novel anti-coagulant with improved efficacy and safety (comparing it with heparin or wt-hirudin) because of its unique bi-functional features.

\section{Results}

Analysis of r-RGD-hirudin-pPIC9K expression plasmid

The designed clone was constructed, identified by restriction map, and was subsequently confirmed by sequencing analysis.

Integration of r-RGD-hirudin encoding gene into Pichia pastoris chromosome

As $700 \mathrm{bp}$ and $2.2 \mathrm{~kb}$ bands of PCR products were observed in $1.0 \%$ agarose gel electrophoresis, we confirmed that the expression plasmid was integrated into the Pichia pastoris chromosome and that phenotype was $\mathrm{Mut}^{+}$.

Expression of r-RGD-hirudin in Pichia pastoris

$\mathrm{Mut}^{+}$transformants were grown in shake flask and screened for those that secreted r-RGD-hirudin to the growth medium with high level. After 2 days of methanol induction, the anti-thrombin activity of expression product in the culture was up to $3,500 \mathrm{ATU} / \mathrm{ml}$ as determined by fibrinogen solidification assay. SDS-PAGE showed that the expression level of r-RGD-hirudin was as high as $85 \%$ of the culture (Fig. 1). Analysis by LC/MS indicated that the molecular weight of r-RGD-hirudin was about $7 \mathrm{kDa}$ (Fig. 2).

Scale up production of r-RGD-hirudin and its in vitro anti-thrombin activity assay

After 2 days of fermentation, the media were collected by centrifugation, and then concentrated by ultra-filtration. The concentrated media were subjected to gel filtration and anion exchange chromatography. The purity of r-RGDhirudin was up to $97 \%$ and the specific activity was over 12,000 ATU/mg. About $1.5 \mathrm{~g}$ of purified r-RGD-hirudin was generated from 11 culture.

\section{Platelet aggregation assay}

r-RGD-hirudin was shown to inhibit ADP induced platelet aggregation in a dose-dependent manner, whereas wthirudin did not appear to harbor the same activity (Fig. 3).

The binding of r-RGD-hirudin to platelet was quantified by Average Fluorescence Intensity which was rectified by subtracting values of non-specific binding and blank (Table 1).

Pharmacodynamics study: in the rabbit model to study the anti-thrombotic effects of r-RGD-hirudin

Pathological analysis indicated that the anti-thrombotic effect of r-RGD-hirudin was dose-dependent. The effective dose was only 1/2-1/3 of wt-hirudin (Table 2, Fig. 4). The result of DSA showed that within 3 days of surgery (Fig. 5), in the control group, or groups treated with abciximab or a low dose of r-RGD-hirudin, there were thrombosis in the blood vessels undergone surgery; while

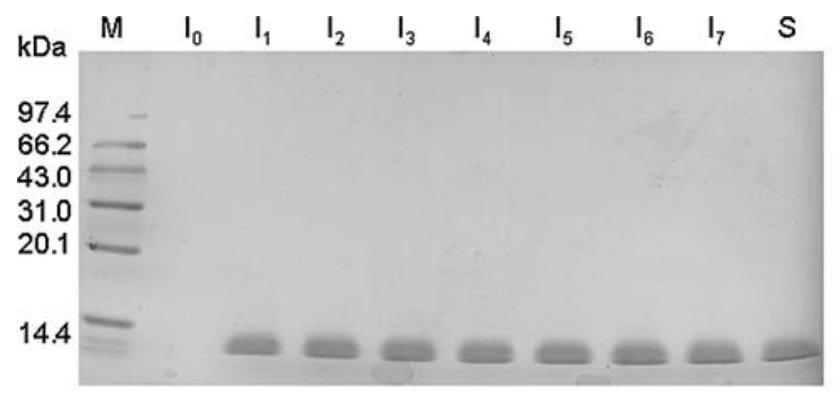

Fig. 1 SDS-PAGE pattern of r-RGD-hirudin in the culture during methanol induction. M: protein marker. $\mathrm{I}_{0}$ : before methanol induction. $\mathrm{I}_{1-7}$ : seven samples with methanol induction for 2 days. S: wt-hirudin. It was same with wt-hirudin that the expression level of r-RGDhirudin was more than $85 \%$. r-RGD-hirudin was excreted into supernatant of culture 
Fig. 2 LC/MS analysis of purified r-RGD-hirudin. The molecular weight of r-RGDhirudin was about 7,031 Da which is consistent with theoretics

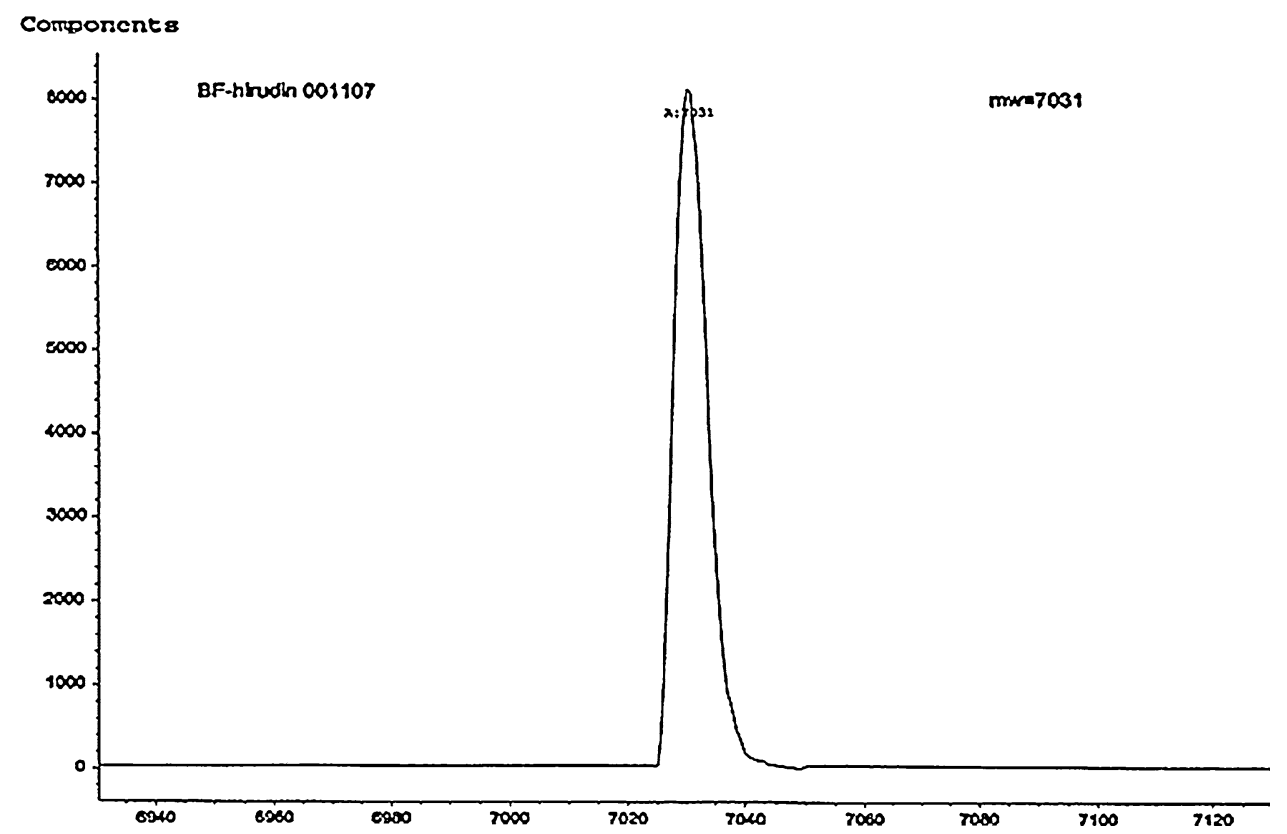

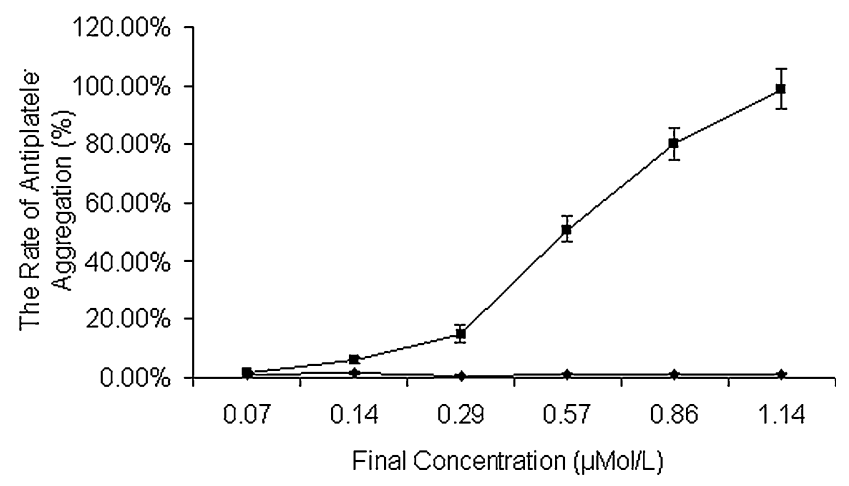

Fig. 3 The effects of r-RGD-hirudin and wt-hirudin on rabbit platelet-aggregation induced by ADP. (ם) r-RGD-hirudin inhibited platelet aggregation induced by ADP in a dose-dependent manner; ( ) wt-hirudin was not capable of inhibiting platelet aggregation induced by ADP; r-RGD-hirudin $0.14 \mu \mathrm{mol} / 1$ could inhibit the platelet aggregation, and its inhibitory effect on the platelet aggregation was dose-response, however, wt-hirudin had no effect on the platelet aggregation which was induced by ADP

in the other three groups, there were no thrombosis and recirculation was complete in the blood vessels. Haematological assay showed that TT, PT, and APTT were prolonged after infusion of r-RGD-hirudin or wt-hirudin, and r-RGD-hirudin was capable of inhibiting platelet aggregation (Fig. 6).

\section{Bleeding time}

Compared with NS control, bleeding time was prolonged after infusion of r-RGD-hirudin for $1.5 \mathrm{~h}$ (especially at $1.0 \mathrm{mg} / \mathrm{kg})$, and wt-hirudin $(1.0 \mathrm{mg} / \mathrm{kg})$ for $1.0 \mathrm{~h}$ (Table 3).
Table 1 Average fluorescence intensity

\begin{tabular}{lc}
\hline $\begin{array}{l}\text { Final concentration of r-RGD-hirudin } \\
(\mu \mathrm{mol} / \mathrm{l})\end{array}$ & $\begin{array}{l}\text { Fluorescence intensity } \\
(\text { Means } \pm \mathrm{SD})\end{array}$ \\
\hline 0.02 & $6.27 \pm 0.13$ \\
0.04 & $13.72 \pm 1.03$ \\
0.09 & $16.99 \pm 1.21$ \\
0.18 & $27.67 \pm 1.57$ \\
0.36 & $37.11 \pm 1.90$ \\
0.88 & $56.78 \pm 2.35$ \\
1.78 & $57.70 \pm 2.54$ \\
\hline
\end{tabular}

$\mathrm{IC}_{50}$ was $0.3 \mu \mathrm{mol} / 1$ which was calculated by linear correlation $(Y=12.25+54.18 X, R=0.96, X$ means final concentration of r-RGD-hirudin and $Y$ means fluorescence intensity)

\section{Discussion}

Thrombin is a central regulator in the coagulation cascade and inflammation process [5]. In the process of venous thrombogenesis, several thrombin inhibitors with pharmacological profiles different from the conventional anticoagulant heparin are currently in clinical use for thromboembolic indications. One of them is the direct thrombin inhibitor recombinant hirudin [6]. In the artery, platelet aggregation may play a crucial role in thrombosis. Platelet aggregation inhibitors, which interfere in the interactions between fibrinogen and its receptor, the GP IIb/IIIa complex, show extreme structural diversity but they share the common functional feature of (RGD) tripeptide segment [7].

We have constructed a fusion gene encoding a novel anti-coagulant, r-RGD-hirudin, and expressed it at high levels in Pichia pastoris. The r-RGD-hirudin is a 
Table 2 Recirculation of rabbit carotid artery on anastomosis area $(* P<0.05)$

\begin{tabular}{llll}
\hline & Thrombosis & Partial recirculation & Completely recirculation \\
\hline NS control $(n=7)$ & $4 / 7$ & $3 / 7$ & $0 / 7$ \\
Abciximab $0.2 \mathrm{mg} / \mathrm{kg}(n=7)$ & $2 / 7$ & $3 / 7$ & $2 / 7$ \\
wt-hirudin $1.0 \mathrm{mg} / \mathrm{kg}(n=7)$ & $0 / 7$ & $2 / 7$ & $5 / 7 *$ \\
r-RGD-hirudin $0.2 \mathrm{mg} / \mathrm{kg}(n=7)$ & $2 / 7$ & $2 / 7$ & $3 / 7$ \\
r-RGD-hirudin $0.5 \mathrm{mg} / \mathrm{kg}(n=7)$ & $0 / 7$ & $3 / 7$ & $4 / 7 *$ \\
r-RGD-hirudin $1.0 \mathrm{mg} / \mathrm{kg}(n=7)$ & $0 / 7$ & $1 / 7$ & $6 / 7 *$ \\
\hline
\end{tabular}

Compared with NS control, r-RGD-hirudin $(0.5,1.0 \mathrm{mg} / \mathrm{kg})$ and wt-hirudin $(1.0 \mathrm{mg} / \mathrm{kg})$ prevented thrombosis at the anastomosis vessels significantly $(* P<0.05)$. However, in abciximab $(0.2 \mathrm{mg} / \mathrm{kg})$ and $\mathrm{r}-\mathrm{RGD}$-hirudin $(0.2 \mathrm{mg} / \mathrm{kg})$ treatment groups, thrombosis was obvious. The function of the r-RGD-hirudin $(0.5 \mathrm{mg} / \mathrm{kg})$ was the same as that of the wt-hirudin $(1.0 \mathrm{mg} / \mathrm{kg})$. The antithrombotic effect of r-RGD-hirudin was dose-dependent

Fig. 4 Pathological result. (1) NS control group; (2) abciximab $0.2 \mathrm{mg} / \mathrm{kg}$; (3) wt-hirudin

$1.0 \mathrm{mg} / \mathrm{kg}$; (4) r-RGD-hirudin

$0.2 \mathrm{mg} / \mathrm{kg}$; (5) r-RGD-hirudin

$0.5 \mathrm{mg} / \mathrm{kg}$; (6) r-RGD-hirudin

$1.0 \mathrm{mg} / \mathrm{kg}$ : In group 1, thrombi were observed in anastomosis vessels; in group 2 and 4, after 3 days of anti-thrombotic therapy, vessels were partial patent. On the contrary, in other 3 groups, animals were treated by wt-hirudin $(1.0 \mathrm{mg} / \mathrm{kg})$, r-RGD-hirudin $(0.5 \mathrm{mg} / \mathrm{kg}$ or $1.0 \mathrm{mg} / \mathrm{kg}$ ) for 3 days, vessels were completely patent
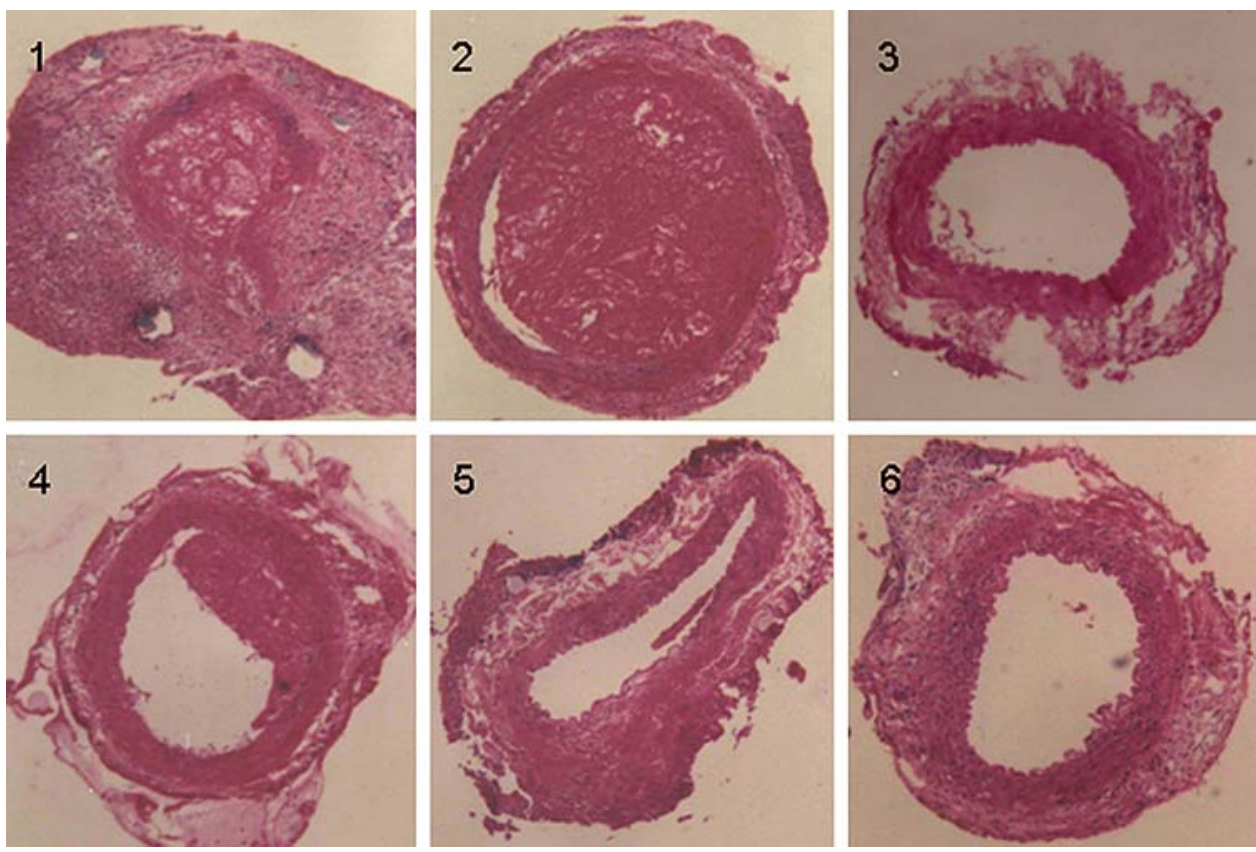

bi-functional molecule containing domain for specific thrombin inhibition and RGD sequence for blocking platelet aggregation. In animal studies, we demonstrated that r-RGD-hirudin was able to prevent thrombogenesis more effectively than both heparin and wt-hirudin.

In r-RGD-hirudin, the RGD tripeptide was fused into the loop region within the wt-hirudin molecule. The structure and function of wt-hirudin were not changed, and the fusion RGD tripeptide was able to bind to GP IIb/IIIa of platelet and inhibit platelet aggregation at the mean time. Fibrinogen solidification assay showed that r-RGD-hirudin strongly inhibited thrombin, and the specific anti-thrombin activity was similar to that of wt-hirudin. Molecular docking of r-RGD-hirudin on thrombin indicated that RGD tripeptide was always at the surface of the complex, which means the RGD tripeptide could bind to GP IIb/IIIa receptor freely. This is consistent with the finding that r-RGD-hirudin could inhibit platelet aggregation in vitro and in vivo assay.
Microsurgery is currently an established technique being used in various surgical specialties such as plastic surgery, neurosurgery, and transplantation surgery [8]. Microvascular free tissue transfers at present results in a very high failure rate due primarily to thrombosis of the blood vessels at the anastomotic site. Previous research in the field has shown that anticoagulants such as heparin can reduce the rate of thrombosis. Although heparin is being used as anti-coagulants in microsurgery, bleeding problems have been a troublesome side effect. Recent studies have shown that wt-hirudin may be useful in eliminating unwanted bleeding episodes in the face of effective anti-coagulation [9]. The development of new anti-coagulants has been pursued with the aim of finding more effective, safer and/or more convenient therapies. So, this model was suitable for pharmacodynamics studies which focused on anti-coagulant research.

Our r-RGD-hirudin contains both the native hirudin sequence and an additional RGD sequence. It is capable of 
Fig. 5 The result of DSA. Ten minutes after operation, DSA showed the anastomosis is successful (Data was not shown). (1) NS control group, (2) abciximab $0.2 \mathrm{mg} / \mathrm{kg}$,

(3) wt-hirudin $1.0 \mathrm{mg} / \mathrm{kg}$,

(4) r-RGD-hirudin $0.2 \mathrm{mg} / \mathrm{kg}$,

(5) r-RGD-hirudin $0.5 \mathrm{mg} / \mathrm{kg}$,

(6) r-RGD-hirudin $1.0 \mathrm{mg} / \mathrm{kg}$,

(A) Thrombus in the carotid artery: in group1, 2 and 4, 3 days later of surgery, DSA showed thrombus was formed in the vessel. In group3, the vessel was partial patent. In group 5 and 6 , the vessel was completely patent

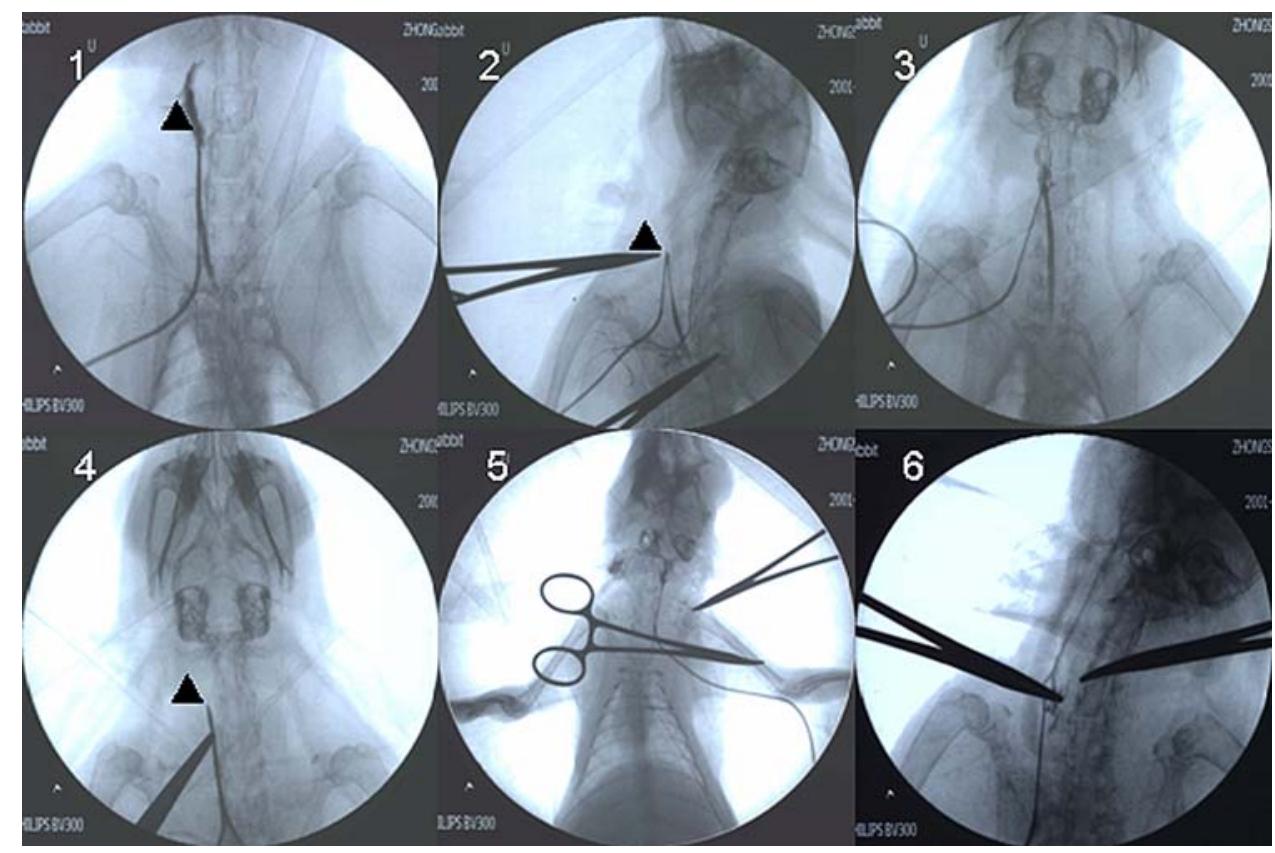

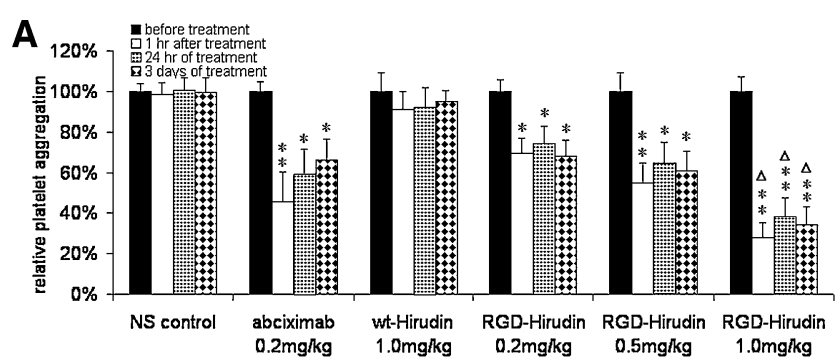



Fig. 6 Determination of coagulation parameters before and after treatment. r-RGD-hirudin inhibited platelet aggregation induced by ADP and the inhibitory effect was dose-response (a); wt-hirudin does not possess this effect. Abciximab also can inhibit platelet aggregation induced by ADP. Compared with before treatment $* P<0.05$, $* * P<0.01$; wt-hirudin $(1.0 \mathrm{mg} / \mathrm{kg})$ compared with $\mathrm{r}$-RGD-hirudin

acting as an anti-thrombin agent as well as an inhibitor of platelet aggregation. Pathological results showed that the anti-thrombotic effect of r-RGD-hirudin was dose-dependent. Its effective dose was less than the half dose of wt-hirudin. The result of DSA showed that within 3 days of surgery, the control group, and groups treated with abciximab or a low dose of r-RGD-hirudin appeared with thrombosis, while in the other three groups, the blood
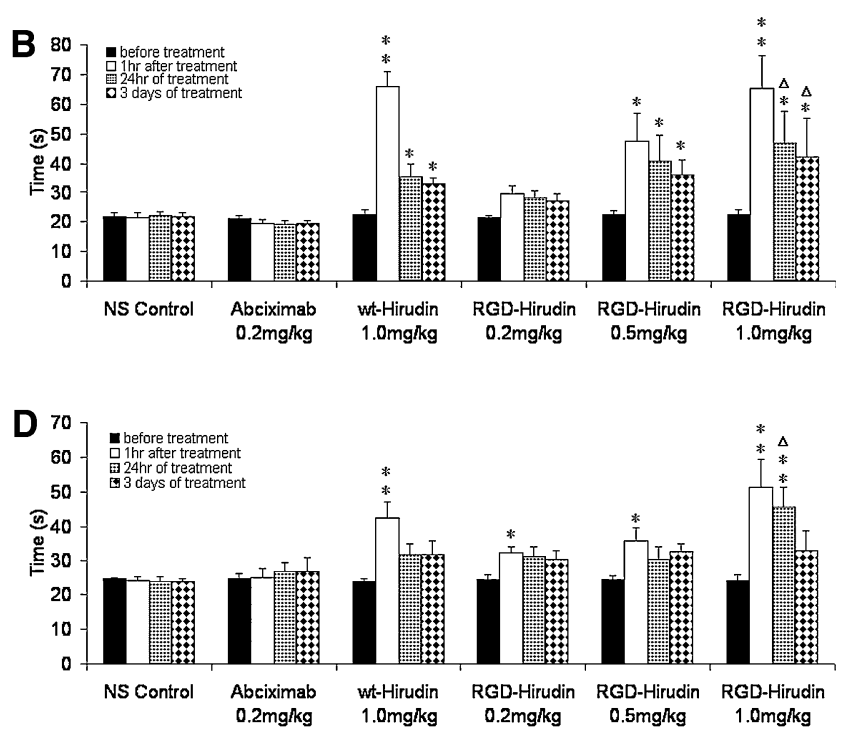

$(1.0 \mathrm{mg} / \mathrm{kg}),(\Delta) P<0.05$. After infusion of $\mathrm{r}$-RGD-hirudin or wt-hirudin, TT (b), PT (c) and APTT (d) were prolonged significantly. The anti-thrombotic effect of r-RGD-hirudin was dose-dependent. (Compared with before treatment $* P<0.05$, $* * P<0.01$ ). Compared with wt-hirudin $(1.0 \mathrm{mg} / \mathrm{kg}), \mathrm{r}$-RGD-hirudin $(1.0 \mathrm{mg} / \mathrm{kg})$ inhibited thrombin more effectively than wt-hirudin. ( $\Delta) P<0.05$

vessels completely patent. In r-RGD-hirudin treated group, no bleeding side-effects were observed.

However, in safety evaluation, r-RGD-hirudin $(30 \mathrm{mg} /$ $\mathrm{kg} / \mathrm{day}$ ) was infused into six rhesus monkeys (3/sex) for 14 consecutive days; one monkey/sex was allowed to recover without further treatment for an additional 14 days. Internal organ bleeding occurred in the treatment period, but all side-effects disappeared in the recovery period. This result 
Table 3 Bleeding time

\begin{tabular}{llllr}
\hline & $0.5 \mathrm{~h}$ & $1.0 \mathrm{~h}$ & $1.5 \mathrm{~h}$ & $2.0 \mathrm{~h}$ \\
\hline NS control $(n=7)$ & $107.7 \pm 21.1$ & $100.2 \pm 13.8$ & $103.0 \pm 10.0$ & $104.2 \pm 12.0$ \\
wt-Hirudin $1.0 \mathrm{mg} / \mathrm{kg}(n=7)$ & $146.8 \pm 12.5^{*}$ & $131.6 \pm 16.6^{*}$ & $120.0 \pm 17.9$ & $116.9 \pm 15.7$ \\
r-RGD-hirudin $0.2 \mathrm{mg} / \mathrm{kg}(n=7)$ & $106.7 \pm 21.1$ & $118.8 \pm 35.3$ & $100.0 \pm 26.0$ & $100.5 \pm 17.0$ \\
r-RGD-hirudin $0.5 \mathrm{mg} / \mathrm{kg}(n=7)$ & $134.3 \pm 36.2$ & $121.0 \pm 25.1$ & $116.7 \pm 28.0$ & $102.5 \pm 26.8$ \\
r-RGD-hirudin $1.0 \mathrm{mg} / \mathrm{kg}(n=7)$ & $149.5 \pm 25.4^{*}$ & $130.8 \pm 24.3^{*}$ & $123.2 \pm 20.5$ & $102.5 \pm 14.4$ \\
\hline
\end{tabular}

Compared with NS control, bleeding time was prolonged after infusion of r-RGD-hirudin for $1.5 \mathrm{~h}(1.0 \mathrm{mg} / \mathrm{kg})$ and wt-hirudin $(1.0 \mathrm{mg} / \mathrm{kg})$ for 1.0 h. $* P<0.05$

showed, after infusion of r-RGD-hirudin, bleeding was not apparent and reversible. (Data was not shown).

\section{Conclusion}

The initial data from this pilot study demonstrate the antithrombotic performance of r-RGD-hirudin. r-RGD-hirudin may be a more effective agent for anti-coagulation and antithrombosis in post-anastomosis surgery. We predicate that r-RGD-hirudin will be able to replace heparin or wt-hirudin and reduce the bleeding rate because of its bi-functional action and with a much lower dosage than wt-hirudin.

\section{Materials and methods}

\section{Materials}

Enzymes and chemicals were obtained from BRL (USA) or Sigma Chemical (USA). A multi-functional plateletaggregation-meter was obtained from Shanghai Sylong Medical Apparatus and Instruments Co., Ltd.

Male rabbits (77) weighing 2.2-2.6 kg were used in the pharmacodynamics study to evaluate safety.

\section{Construction of r-RGD-hirudin}

The r-RGD-hirudin gene was synthesized in the Key Laboratory of Molecular Medicine at Fudan University. The cDNA encoding r-RGD-hirudin was cloned into the plasmid pPIC9K. The resulting expression vector was transformed into Pichia pastoris GS115. Vector integration into the pichia pastoris chromosome was confirmed by PCR analyses.

Expression of r-RGD-hirudin and determination of antithrombin activity

Ten milliliter of BMGY (yeast extract $1 \%$, peptone $2 \%$, phosphate $100 \mathrm{mmol} / \mathrm{l}$, yeast nitrogen base $1.34 \%$, glycerol
$1 \% \mathrm{pH} 6.0$ ) liquid culture medium was inoculated in a $50 \mathrm{ml}$ conical tube with above seven colonies and incubated overnight at $30^{\circ} \mathrm{C}$ with vigorous shaking $(250 \mathrm{rpm})$ until the culture reached an $\mathrm{OD}_{600}$ reading of $2-3$. Cells were harvested by centrifugation at $4,000 \mathrm{rpm}$ for $10 \mathrm{~min}\left(4^{\circ} \mathrm{C}\right)$. Pellets were re-suspended in $10 \mathrm{ml}$ of BMMY (yeast extract $1 \%$, peptone $2 \%$, phosphate $100 \mathrm{mmol} / \mathrm{l}$, yeast nitrogen base $1.34 \%$, methanol $0.5 \% \mathrm{pH} 6.0$ ) and were incubated at $30^{\circ} \mathrm{C}$ overnight with vigorous shaking $(250 \mathrm{rpm})$. Every $4 \mathrm{~h}$, samples were collected from the above BMMY culture. Supernatant was obtained by centrifugation at 4,000 rpm for $10 \mathrm{~min}$, and the anti-thrombin activity was measured by fibrinogen solidification assay [1].

Fermentation and purification

The clone with high expression level was selected and fermented for 2 days. The culture was centrifuged and the supernatant was ultra-filtrated, followed by gel filtration and anion exchange chromatography [10].

\section{SDS-PAGE and LC-MS}

Samples mixed with $2 \times$ buffer were subjected to $12 \%$ reducing SDS-PAGE. The gel was stained with coomassie brilliant blue R-250, and Pharmacia Imagemaster VDS was used to identify the purity of products. LC-MS was used to identify the molecular weight of r-RGD-hirudin after its purification.

Fibrinogen solidification assay

Fibrinogen solidification assay was used to measure the anti-thrombin activity of r-RGD-hirudin [1]. Two hundred microliter of fresh plasma was added to a $1.5 \mathrm{ml}$ tube; $5 \mu \mathrm{l}$ of supernatant fluid was added to the plasma and mixed by vortexing. Five microliter of $100 \mathrm{NIH}$ units of thrombin were added to the above mixture and allowed to stand for $1 \mathrm{~min}$ : if the plasma did not clot, the supernatant had 100 anti-thrombin units. Thus, consumption of each 1 NIH unit of thrombin is equivalent to 1 anti-thrombin unit. 
Platelet aggregation

Classic turbidity assay was used to measure the anti-platelet aggregation activity of r-RGD-hirudin. Fresh blood was obtained from rabbits. Sodium citrate $(110 \mathrm{mmol} / \mathrm{l})$ was used as the anti-coagulant at a ratio of 1:9 (v/v). Platelet rich plasma (PRP) was obtained by centrifugation at $800 \mathrm{rpm}$ for $10 \mathrm{~min}$, and a second centrifugation at 3,500 rpm for $15 \mathrm{~min}$ was used to prepare platelet-poor plasma (PPP). The PRP was diluted by PPP to a platelet count of $450,000 / \mu 1$. Two hundred microliter of PRP was added in colorimetric cup, with continuous agitation, $5 \mu \mathrm{l}$ of wt-hirudin (control) or purified r-RGD-hirudin was then added. The final concentrations were $0.07,0.14,0.29,0.57,0.86$, and $1.14 \mu \mathrm{mol} / \mathrm{l}$. The colorimetric cups were incubated at $37^{\circ} \mathrm{C}$ for $5 \mathrm{~min}$, and ADP $(20 \mu \mathrm{mol} / 1$ final concentration) was used to induce platelet aggregation. The percentage of aggregation was measured for $5 \mathrm{~min}$ and the percentage of aggregation inhibition was calculated by the following formula: $\mathrm{Ii} \%=$ $\left(\mathrm{PAGm}_{\text {blank }}-\mathrm{PAGm}_{\mathrm{Ci}}\right) / \mathrm{PAGm}_{\text {blank }} \times 100 \%$, where $\mathrm{Ii} \%$ was the inhibitory percentage, PAGmblank was maximum platelet aggregation without wt-hirudin or r-RGD-hirudin, and $\mathrm{PAGm}_{\mathrm{Ci}}$ was maximum platelet aggregation with wt-hirudin or r-RGD-hirudin.

\section{Competitive inhibition assay}

Competitive inhibition assay was used to determine the $\mathrm{IC}_{50}$ of the inhibitive effect of r-RGD-hirudin on platelet aggregation. Flow cytometry was used to determine the binding of r-RGD-hirudin to the platelet [11]. Briefly, in comparison with Clopidogrel, the final concentration was $18 \mathrm{mmol} / \mathrm{l}$. r-RGD-hirudin was mixed with Clopidogrel and platelets (the platelet count was $450,000 / \mu \mathrm{l}$ ). The final concentrations of r-RGD-hirudin were 0.02, 0.04, 0.09, 0.18, 0.36, 0.88 and $1.78 \mu \mathrm{mol} / 1$. ADP ( $20 \mu \mathrm{mol} / 1$ final concentration) was used to induce platelet aggregation. FITC labeled multi-clonal anti-RGD-hirudin antibody was added and platelet was washed by buffer (EDTA- $\mathrm{Na}_{2}: 0.2 \mathrm{mmol} / \mathrm{l}, \mathrm{NaCl}$ : $137 \mathrm{mmol} / \mathrm{l}, \mathrm{KCl}: 2.68 \mathrm{mmol} / \mathrm{l}, \mathrm{MgSO}_{4} \cdot 7 \mathrm{H}_{2} \mathrm{O}: 0.2 \mathrm{mmol} / \mathrm{l}$, $\mathrm{NaH}_{2} \mathrm{PO}_{4} \cdot 2 \mathrm{H}_{2} \mathrm{O}: 0.42 \mathrm{mmol} / \mathrm{l}, \mathrm{NaHCO}_{3}: 11.9 \mathrm{mmol} / \mathrm{l}$, glucose: $5.05 \mathrm{mmol} / \mathrm{l})$ twice.

\section{Pharmacodynamics study}

Forty two male rabbits weighing $2.2-2.6 \mathrm{~kg}$ were used in the study. Nembutal (40 mg/kg b.w.) was used as the anesthetic agent. After exposing the carotid artery with standard procedures, the artery was clamped and clipped. The standard suture closure was then achieved using $10^{\prime} 0^{\prime}$ nylon suture in an interrupted fashion [12].

After operation, anti-coagulants were infused. All drugs were administered in an intravenous bolus dose followed by repeatedly subcutaneous injection in an equivalent dose for 3 days (twice a day). Group 1 was infused with normal saline as the control; group 2 was infused with abciximab $0.2 \mathrm{mg} / \mathrm{kg}$; group 3 was infused with wt-hirudin $1.0 \mathrm{mg} / \mathrm{kg}$; group 4 was infused with r-RGD-hirudin $0.2 \mathrm{mg} / \mathrm{kg}$; group 5 was infused with r-RGD-hirudin $0.5 \mathrm{mg} / \mathrm{kg}$ and group 6 was infused with r-RGD-hirudin $1.0 \mathrm{mg} / \mathrm{kg}$ [13, 14].

Digital subtraction angiography (DSA) was used for $10 \mathrm{~min}, 3$ days after surgery. Vessels on the anastomosis area were separated, and slices were prepared.

Blood samples were collected before treatment (control), 1, $24 \mathrm{~h}$ and 3 days after treatment. TT, PT, APTT, and maximum platelet aggregation (PAGm) induced by ADP were determined.

\section{Determination of bleeding time}

Thirty five male rabbits weighing 2.2-2.6 kg were used in the study. A $0.5 \mathrm{~cm}$-long wound was cut on each rabbits auricle (avoiding damnifying the artery and vein). The auricle was dipped in $37^{\circ} \mathrm{C}$ NS, and simultaneously, bleeding time was determined until bleeding stopped.

Group 1 was infused with normal saline as the control; group 2 was infused with wt-hirudin $1.0 \mathrm{mg} / \mathrm{kg}$; group 3 was infused with r-RGD-hirudin $0.2 \mathrm{mg} / \mathrm{kg}$; group 4 was infused with r-RGD-hirudin $0.5 \mathrm{mg} / \mathrm{kg}$, and group 5 was infused with r-RGD-hirudin $1.0 \mathrm{mg} / \mathrm{kg}$ [5]. Bleeding time was determined at $0.5,1.0,1.5$, and $2.0 \mathrm{~h}$ time points after infusion.

\section{Statistical analysis}

Data are expressed as means \pm SEM. One-way analysis of variance (ANOVA) or Student's $t$-test was used where applicable. The differences with $P$-values $<0.05$ were considered statistically significant.

Acknowledgments We thank Prof Coller B.S. for his excellent technical assistance. This study was supported by Shanghai Scientific and Technology Committee (04DZ19205).

Open Access This article is distributed under the terms of the Creative Commons Attribution Noncommercial License which permits any noncommercial use, distribution, and reproduction in any medium, provided the original author(s) and source are credited.

\section{References}

1. Markwardt F, Sturzebecker J, Griessbach U (1970) Hirudin as an inhibitor of thrombin. Meth Enzymol 19:924-932

2. Chang JY (1983) The functional domain of hirudin, a thrombinspecific inhibitor. FEBS Lett 164:307-313

3. Modi NB, Baughman SA, Paasch BD et al (1995) Pharmacokinetics and pharmacodynamics of TP-9201, a GP IIb/IIIa antagonist, in rats and dogs. J Cardiovasc Pharmacol 25:888-897 
4. Adelman B, Gennings C, Strony J et al (1990) Synergistic inhibition of platelet aggregation by fibrinogen-related peptides. Cirs Res 67:941-947

5. Marsh Lyle E, Lewis SD, Lehman ED et al (1998) Assessment of thrombin inhibitor efficacy in a novel rabbit model of simultaneous arterial and venous thrombosis. Thromb Haemost 79(3): 656-662

6. Leadley RJ, Kasiewski CJ, Bostwick JS et al (1997) Comparison of enoxaparin, hirulog, and heparin as adjunctive antithrombotic therapy during thrombolysis with rt-PA in the stenosed canine coronary artery. Thromb Haemost 78(4):1278-1285

7. Coller Barry S (2001) Anti-GP IIb/IIIa drugs: current strategies and future directions. Thromb Haemost 86:427-443

8. Narayanan K, Walenga JM et al (1991) Recombinant hirudininitial observation in reconstructive microsurgery. Haemostasis 21(suppl 1):168-171

9. White CM (2005) Thrombin-directed inhibitors: pharmacology and clinical use. Am Heart J 149(Suppl 1):S54-S60
10. Lehman ED, Joyce JF, Bailey J et al (1993) Expression, purification and characterization of multigram amounts of a recombinant hybrid HV1-HV2 hirudin variant expressed in Saccharomyces cerevisiae. Protein Expr Purif 4:247-255

11. Warkentin TE, Powling MJ, Hardisty RM (1990) Measurement of fibrinogen binding to platelets in whole blood by flow cytometry. Br J Haematol 76:387-394

12. Roesken F, Vollmar B, Rucker M et al (1998) In vivo analysis of antithrombotic effectiveness of recombinant hirudin on microvascular thrombus formation and recanalization. J Vasc Surg 28(3):498-505

13. Zokai K, Piazolo L, Harenberg J et al (2001) Effect of thrombin inhibitors and a glycoprotein IIb/IIIa receptor antagonist in an ex vivo human experimental thrombosis model. Semin Thromb Hemost 27(5):531-536

14. Lavelle SM, MacIomhair M et al (1998) Bleeding times and the antithrombotic effects of high-dose aspirin, hirudin and heparins in the rat. J Ment Sci 167(4):216-220 